\title{
Topics in Catalysis
}

\section{BaFe1-xCuxO3 perovskites as soot oxidation catalysts for Gasoline Particulate Filters (GPF): a preliminary study

$$
\text { --Manuscript Draft-- }
$$

\begin{tabular}{|c|c|c|}
\hline Manuscript Number: & \multicolumn{2}{|l|}{ TOCA-D-18-00118R1 } \\
\hline Full Title: & \multicolumn{2}{|c|}{$\begin{array}{l}\text { BaFe1-xCuxO3 perovskites as soot oxidation catalysts for Gasoline Particulate Filters } \\
\text { (GPF): a preliminary study }\end{array}$} \\
\hline Article Type: & \multicolumn{2}{|c|}{ Catalysis and Automotive Pollution Control } \\
\hline \multirow[t]{3}{*}{ Funding Information: } & $\begin{array}{l}\text { MINECO-UE (FEDER) } \\
\text { (CTQ2015-64801-R) }\end{array}$ & Dr M. J. Illán-Gómez \\
\hline & $\begin{array}{l}\text { Generalitat Valenciana } \\
\text { (ACIF 2017/221) }\end{array}$ & Ms. V. Torregrosa- Rivero \\
\hline & $\begin{array}{l}\text { Generalitat Valenciana } \\
\text { (PROMETEO/2018/076) }\end{array}$ & Not applicable \\
\hline Abstract: & \multicolumn{2}{|c|}{$\begin{array}{l}\text { A series of BaFe1-xCuxO3 catalysts ( } \mathrm{x}=0,0.1,0.3 \text { and } 0.4 \text { ) have been synthetized, } \\
\text { characterized and used for soot oxidation in Gasoline Direct Injection (GDI) exhaust } \\
\text { conditions. The characterization of the catalysts (by BET, ICP-OES, XRD, XPS, H2- } \\
\text { TPR and O2-TPD) reveals that copper is incorporated into the perovskite lattice } \\
\text { leading to: } i \text { ) the distortion of the original hexagonal perovskite structure for the lowest } \\
\text { copper content catalyst (BFC1) and the modification of the structure, from hexagonal to } \\
\text { cubic, for the catalysts with higher copper content (BFC3 and BFC4), ii) the generation } \\
\text { of a BaOx-CuOx oxide as minority segregated phase for BFC4 catalyst, iii) the } \\
\text { increase in the amount of oxygen surface vacancies for BFC3 and BFC4 catalysts, and } \\
\text { iv) the decrease in the total amount of O2 released during O2-TPD experiments. All } \\
\text { the BaFe1-xCuxO3 perovskites are active for soot oxidation under the highest } \\
\text { demanding GDI exhaust conditions (regular stoichiometric GDI operation, i.e., } 0 \% \text { O2). } \\
\text { The catalyst with the highest copper content (BFC4) shows the highest soot } \\
\text { conversion, related to its largest amount of -oxygen evolved, and, to the presence of a } \\
\text { high amount of copper species (as BaOx-CuOx - oxide) on its surface. }\end{array}$} \\
\hline Corresponding Author: & \multicolumn{2}{|c|}{$\begin{array}{l}\text { M. J. Illán-Gómez } \\
\text { Universitat d'Alacant } \\
\text { San Vicente del Raspeig, Alicante (Spain) SPAIN }\end{array}$} \\
\hline \multicolumn{3}{|l|}{$\begin{array}{l}\text { Corresponding Author Secondary } \\
\text { Information: }\end{array}$} \\
\hline Corresponding Author's Institution: & \multicolumn{2}{|l|}{ Universitat d'Alacant } \\
\hline \multicolumn{3}{|l|}{$\begin{array}{l}\text { Corresponding Author's Secondary } \\
\text { Institution: }\end{array}$} \\
\hline First Author: & \multicolumn{2}{|l|}{ M. J. Illán-Gómez } \\
\hline \multicolumn{3}{|l|}{ First Author Secondary Information: } \\
\hline \multirow[t]{5}{*}{ Order of Authors: } & \multicolumn{2}{|l|}{ M. J. Illán-Gómez } \\
\hline & \multicolumn{2}{|l|}{ C. Moreno-Marcos } \\
\hline & \multicolumn{2}{|l|}{ V. Torregrosa- Rivero } \\
\hline & \multicolumn{2}{|l|}{ V. Albaladejo-Fuentes } \\
\hline & \multicolumn{2}{|l|}{ M.S. Sánchez- Adsuar } \\
\hline \multicolumn{3}{|c|}{ Order of Authors Secondary Information: } \\
\hline Author Comments: & \multicolumn{2}{|c|}{ All the modifications carried out in the manuscript have been marked in blue colour. } \\
\hline Response to Reviewers: & \multicolumn{2}{|c|}{$\begin{array}{l}\text { Answer to Reviewer \#1 } \\
\text { The paper deals with a series of } \mathrm{BaFe} 1-\mathrm{xC} \mathrm{CuXO} 3 \text { catalysts }(\mathrm{x}=0,0.1,0.3 \text { and } 0.4) \text { that } \\
\text { have been synthesized, characterized and used for soot oxidation in Gasoline Diesel } \\
\text { Injection (GDI) exhaust conditions. }\end{array}$} \\
\hline
\end{tabular}


The manuscript is well write and organized, the data are of good quality and the results well described and correlated with the morphological characterization.

However, minor point should be clarified before publication.

The authors kindly thank the reviewer comments that have been considered in order to improve the quality of the manuscript. Below, the authors answer to each reviewer comment:

1-Why the Authors define the flow of $\mathrm{He}$ as the correct way to simulate the regular stoichiometric GDI operation?

In the reference 6 ( $T$. Boger et al. "Oxidation of Soot (Printex U) in Particulate Filters Operated on Gasoline Engines"), it is indicated that essentially no NO2 and O2 are available for soot oxidation under normal stoichiometric GDI operation. Consequently, in the manuscript the highest demanding GDI condition, that is $0 \% \mathrm{O} 2$, has been selected in order to be in the worst possible conditions. Note that also the selected surrogated soot (Printex $U$ ) represents the least reactive fraction of particulate matter.

2-The distortion of hexagonal structure and/or the transformation into the cubic structure have been confirmed by a Rietveld analysis?

The results of the Rietveld analysis confirm the structural modification detected by $\mathrm{XRD}$. A sentence indicating this fact has been added to the manuscript:

"This structural modification (which has been confirmed by the Rietveld analysis shown in Figure S1 in Supplementary information), was previously observed for other bariumbased perovskites $[13,14,17]$ and also for Sn-doped BaFeO3 perovskites [18], seems to evidence the copper introduction into the perovskite lattice..",

3-Does the Cu segregation up to a certain load of $\mathrm{Cu}$ influence the catalytic activity? As it is discussed in the Catalytic activity section, the presence of copper species as segregated phase (BaOx-CuOx) seems to justify that BFC4 presents the highest activity as copper oxides are a well-known catalysts for oxidation reaction. However, it is worth indicating that the copper species segregated in the BFCX catalyst are ascribed to a $\mathrm{BaOx}-\mathrm{CuOx}$ mixed oxide, not to $\mathrm{CuO}$, as it is mentioned in the manuscript:

"A BaOx-CuOx oxide (with estimated general stoichiometry of $\mathrm{BaCuO} 2$ ) appears as a minority segregated phase in the XRD diffractogram of the BFC4 perovskite (the highest copper content catalyst)."

4-The comparison with the uncatalyzed soot oxidation and with other traditional catalytic materials used in this process could be useful to valorize the reported results. The comparison with both uncatalyzed and other traditional catalytic materials has been included in the revised version. The following sentences have been added: "The CO2 profile corresponding to uncatalyzed soot oxidation has not been included as $\mathrm{CO} 2$ is not detected (reaction atmosphere composed by $100 \% \mathrm{He}$ )."

"This value increases with the copper content from $29 \%$ for BFC0, to $44 \%$ for BFC1, $69 \%$ for BFC3 and $94 \%$ for BFC4. These results agree with that reported for coppersupported Ceria-zirconia catalysts for soot oxidation in GDI conditions [9]."

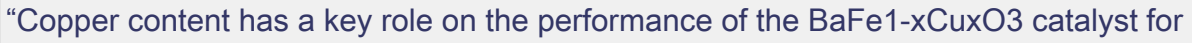
soot oxidation, which is in agreement with previous reports focused on diesel soot removal [13-17, 27-30] and with that reported for copper-supported Ceria-zirconia catalysts for soot oxidation in GDSI conditions [9]."

Answer to Reviewer \#2

The authors synthesized composite oxides of $\mathrm{Cu}, \mathrm{Fe}$ and $\mathrm{Ba}$ by a citrate sol-gel method, and investigated the properties and activities of the compounds obtained by their composition ratio. It is interesting to analyze the relationship between characteristics of the obtained compounds and their activity. However, the discussion of the data obtained is insufficient. Therefore, the additional information and discussion should be provided for the readers. Detailed comments are as follows:

The authors kindly thank the reviewer comments that have been considered in order to improve the quality of the manuscript. Below, the authors answer to each reviewer comment:

General comments:

1) In Figure 1(b), O2-TPD measurements were performed and oxygens were ascribed to three species at each temperature range. In addition, $\beta$-oxygen was effective to oxidize soot in the next section 3.2. Therefore, I think that not only the total amount of 
desorbed oxygen but also the amount of $\beta$-oxygen should be compared with the catalytic activity.

We totally agree with reviewer, in fact, we point out the relationship between catalytic activity for soot oxidation and amount of $\beta$-oxygen. Attending the comment of the reviewer, an d in order to show more clearly this fact, we estimated the amount of this type of oxygen by subtracting the amount of $\mathrm{O} 2$ not consumed during soot oxidation (that is the $\mathrm{O} 2$ evolved shown in Figure $2 \mathrm{~b}$ ) from the total amount of $\mathrm{O} 2$ released by the catalysts featured in Figure 1b..The data confirm that BFC4 evolves the largest amount of $\beta$-oxygen among the iron containing catalysts $(70 \mathrm{~mol} / \mathrm{g}$ cat (BFC1) $>31$ $\mathrm{mol} / \mathrm{g}$ cat $(\mathrm{BFC} 3)>118 \mathrm{~mol} / \mathrm{g}$ cat (BFC4)). In this sense, the following paragraph has been added:

"Based on this assumption, the amount of $\beta$ oxygen has been estimated by subtracting the amount of $\mathrm{O} 2$ not consumed during soot oxidation (that is the $\mathrm{O} 2$ evolved shown in Figure $2 \mathrm{~b}$ ) from the total amount of $\mathrm{O} 2$ released by the catalysts featured in Figure $1 \mathrm{~b}$.. The data confirm that BFC4 evolves the largest amount of $\beta$-oxygen among the iron containing catalysts $(70 \mathrm{~mol} / \mathrm{g}$ cat $(\mathrm{BFC} 1)>31 \mathrm{~mol} / \mathrm{g}$ cat $(\mathrm{BFC} 3)>118 \mathrm{~mol} / \mathrm{g}$ cat (BFC4))."

2) Have you evaluated the activity of Ba-Cu mixed-oxide? It is desirable to list iron-free catalyst synthesized in the same way as a reference.

In the manuscript we incorrectly denominate "Ba-Cu mixed oxide" to the mixture of $\mathrm{BaOx}$ and $\mathrm{CuOx}$ oxide that we have identified by a XRD peak which, tentatively, correspond to a general stoichiometry $\mathrm{BaCuO} 2$ that is an ideal composition corresponding to $\mathrm{BaO}$ and $\mathrm{CuO}$ oxide. To solve this issue, we have modified the denomination along the text of the revised version of the manuscript.

In relation to the second demand, the authors have checked the reproducibility of the $\mathrm{BFC} 4$ catalyst by this synthesis route and $\mathrm{BaCuO} 2$ phase is always identified as segregated phase in this catalyst by XRD. This result allows suggesting that in this catalyst the copper content exceed the metal amount that can be incorporated into the perovskite $\mathrm{BaFeO} 3$ lattice. Additionally, $\mathrm{BaOx}-\mathrm{CuOx}$ mixed oxide was synthesized by means of this sol-gel route in order to prepare a reference material. Unfortunately, the catalyst obtained by this method is a highly heterogeneous material ( $\mathrm{BaCuO2}-\mathrm{CuO}-$ $\mathrm{BaO}$ ) that could not be tested for soot oxidation.

3) In this paper, $\mathrm{BaFe} 1-\mathrm{xCuxO} 3$ oxidized soot by using the oxygen in the catalyst. Can these compounds work as a catalyst? Does the catalyst cooled in air to room temperature after activity evaluation show the same activity? If these compounds do not work as a catalyst, I hope your suggestion for countermeasure against them. In order to probe the catalytic role of perovskite, two consecutive TPR experiments (with a cooling down in air between first and second one) have been successfully carried out. To illustrate this issue, the following sentence has been included in the revised version of the manuscript:

"As the performance of BFC4 is hold during a second cycle of oxidation reaction in TPR conditions (cooling down to room temperature in synthetic air after the first TPR cycle, following by addition of an identical amount of surrogated soot to carry out the second cycle), the catalytic role seems to be probed."

4) Please propose your future plans. Oxidize in lower temperature, improve the heat durability, etc.

The following paragraph has been added to the new version of the manuscript in order to explain the future work using these catalysts:

"In order to complete this study, deeper analysis of the activity and stability of catalysts, in isothermal reaction conditions, as well as under diesel conditions for comparative purpose, is now in process."

Specific comment:

1) Abstract line2 and keywords: Not "Gasoline Diesel injection" but "Gasoline Direct injection

2) 2. Experiment line2: Not "Ba(CH3COOH)2" but "Ba(CH3COO)2"

3) 2. Experiment line5 and 7: Not "ammonia" but "ammonia solution or aqueous ammonia"

4) 3. Results and discussion: Not "Cu/Ba+Ti+Cu and $\mathrm{OL} / \mathrm{Ba}+\mathrm{Ti}+\mathrm{Cu}$ " but

"Cu/Ba+Fe+Cu and $\mathrm{OL} / \mathrm{Ba}+\mathrm{Fe}+\mathrm{Cu} "$

All the specific comments indicated have been considered and modified in the revised version of the manuscript. 


\title{
$\mathrm{BaFe}_{1-\mathrm{x}} \mathrm{Cu}_{\mathrm{x}} \mathrm{O}_{3}$ perovskites as soot oxidation catalysts for Gasoline Particulate Filters (GPF): a preliminary study
}

\section{Moreno-Marcos, V. Torregrosa-Rivero, V. Albaladejo-Fuentes, M.S. Sánchez-Adsuar, M.J. Illán-Gómez*}

Departamento de Química Inorgánica, Facultad de Ciencias, Universidad de Alicante, Ap. 99, Alicante, E-03080.

*illan@ua.es

\begin{abstract}
A series of $\mathrm{BaFe}_{1-\mathrm{x}} \mathrm{Cu}_{x} \mathrm{O}_{3}$ catalysts $(\mathrm{x}=0,0.1,0.3$ and 0.4$)$ have been synthetized, characterized and used for soot oxidation in Gasoline Direct Injection (GDI) exhaust conditions. The characterization of the catalysts (by BET, ICP-OES, XRD, XPS, $\mathrm{H}_{2}-\mathrm{TPR}$ and $\mathrm{O}_{2}-\mathrm{TPD}$ ) reveals that copper is incorporated into the perovskite lattice leading to: i) the distortion of the original hexagonal perovskite structure for the lowest copper content catalyst (BFC1) and the modification of the structure, from hexagonal to cubic, for the catalysts with higher copper content (BFC3 and BFC4), ii) the generation of a $\mathrm{BaOx}-\mathrm{CuOx}$ oxide as minority segregated phase for BFC4 catalyst, iii) the increase in the amount of oxygen surface vacancies for BFC3 and BFC4 catalysts, and iv) the decrease in the total amount of $\mathrm{O}_{2}$ released during $\mathrm{O}_{2}$-TPD experiments. All the $\mathrm{BaFe}_{1-\mathrm{x}} \mathrm{Cu}_{x} \mathrm{O}_{3}$ perovskites are active for soot oxidation under the highest demanding GDI exhaust conditions (regular stoichiometric GDI operation, i.e., $0 \% \mathrm{O}_{2}$ ). The catalyst with the highest copper content (BFC4) shows the highest soot conversion, related to its largest amount of $\beta$-oxygen evolved, and, to the presence of a high amount of copper species (as $\mathrm{BaOx}-\mathrm{CuOx}$ - oxide) on its surface .
\end{abstract}

\section{Keywords:}

Fe-based perovskite, Gasoline Direct Injection (GDI) exhaust, soot oxidation catalysts, Gasoline Particulate Filter (GPF).

Running title:

$\mathrm{BaFe}_{1-\mathrm{x}} \mathrm{Cu}_{x} \mathrm{O}_{3}$ perovskite catalysts for GPF 


\section{Introduction}

Nowadays, it is widely accepted the high toxicity of particulate matter (PM or soot), which is plentiful in urban areas and it is mainly generated by internal combustion engines. In Europe, transport sector generates $14 \%$ of PM2.5 (particulates smaller than $2.5 \mu \mathrm{m}$ ), the most dangerous fraction. Consequently, current European emissions legislation (Euro 6c) for new passengers vehicles equals or reduces the Particulates Numbers (PN) generated by Gasoline Direct Injection (GDI) to the level previously established for Diesel engines [1]. GDI vehicles have been introduced as a more efficient technology than diesel vehicles, since they show significant reduction of fuel consumption and $\mathrm{CO}_{2}$ emissions [2]. Thus an increase in European and US market of GDI cars is expected in a near future. To meet current European emission legislation, the introduction of Gasoline Particulate Filter (GPF) is mandatory for GDI vehicles as Diesel Particulate Filter (DPF) was for Diesel cars. In both cases, periodical regeneration of the filter is needed because soot accumulated in the channels of the filter causes negative effects on engine and a decrease in the fuel economy [3-5]. As the working conditions of GPF are different to that of DPF in diesel exhaust $\left(\mathrm{O}_{2}\right.$ is only available during fuel cuts) [6-8], catalysts able to oxidize soot with low partial pressure of oxygen, or even in the total absence of oxygen, have to be developed. However, the soot oxidation reaction in the high demanding GDI exhaust conditions has not been reported as much as Diesel soot oxidation [7-9]. Among the different catalysts proposed for soot oxidation, mixed oxides with perovskite structure (general formula $\mathrm{ABO}_{3}$ ) are very attractive as their properties depend on the nature of A and B cations and, consequently, its composition can be fitted [10] to the requirements of the oxidation reaction. In fact, perovskites are a promising alternative as soot oxidation catalysts in DPF conditions [11-16]. In previous reports [13,14], the beneficial effect of copper partially incorporated into the structure of $\mathrm{BaTiO}_{3}$ and $\mathrm{BaMnO}_{3}$ perovskites for $\mathrm{NO}_{2}$-assisted diesel soot oxidation has been shown. Recently, Hernández et al. $[7,8]$ have reported that iron-based perovskites are interesting as soot oxidation catalysts in GDI exhaust conditions $\left(\begin{array}{lll}1 \% & \mathrm{O}_{2}\end{array}\right)$. Considering this background, the aim of this paper is to carry out a preliminary study about the effect of the partial substitution of $\mathrm{B}$ cation by copper in the properties of a $\mathrm{BaFeO}_{3}$ perovskite which will determine its catalytic performance for soot oxidation. Thus, a series of $\mathrm{BaFe}_{1-\mathrm{x}} \mathrm{Cu}_{\times} \mathrm{O}_{3}$ catalysts $(x=0,0.1,0.3$ and 0.4$)$ has been synthetized, characterized and used for soot 
oxidation in the highest demanding GDI exhaust conditions (regular stoichiometric GDI operation, i.e., $0 \% \mathrm{O}_{2}$ ) in order to determine the ability of the mixed-oxides as catalysts for GPF.

\section{Experimental}

$\mathrm{BaFe}_{1-\mathrm{x}} \mathrm{Cu}_{x} \mathrm{O}_{3}$ catalysts $(\mathrm{x}=0,0.1,0.3,0.4)$ were prepared by a citrate sol-gel method. $\mathrm{Ba}\left(\mathrm{CH}_{3} \mathrm{COO}\right)_{2}$ (Sigma-Aldrich, 99\%), $\mathrm{Fe}\left(\mathrm{NO}_{3}\right)_{2} \cdot 9 \mathrm{H}_{2} \mathrm{O}$ (Sigma-Aldrich, 97\%), $\mathrm{Cu}\left(\mathrm{NO}_{3}\right)_{2} \cdot 3 \mathrm{H}_{2} \mathrm{O}$ (Panreac, 99\%) were used as metal precursors. In brief, a 1M citric acid solution with 1:2 molar ratio with respect to barium was prepared and heated up to $60^{\circ} \mathrm{C}$. The $\mathrm{pH}$ of this solution was increased to 8.5 by drop wise ammonia solution addition. Afterwards, the stoichiometric amounts of barium, iron, and copper precursors were added to the solution, following this order. Once the precursor salts were dissolved, the $\mathrm{pH}$ value was readjusted to 8.5 with ammonia. The solution was kept at $65^{\circ} \mathrm{C}$ for $5 \mathrm{~h}$ and dried at $90^{\circ} \mathrm{C}$ for $48 \mathrm{~h}$. The dried gel was calcined at $150^{\circ} \mathrm{C}$ for $1 \mathrm{~h}$ and then, at $850^{\circ} \mathrm{C}$ for $6 \mathrm{~h}[13]$.

A Perkin-Elmer device, model Optima 4300 DV, was used for measuring copper content by ICPOES. The BET surface area was determined by $\mathrm{N}_{2}$ adsorption at $-196^{\circ} \mathrm{C}$ in an Autosorb-6B instrument from Quantachrome. For the identification of phases and crystalline structures, X-ray diffraction (XRD) was used. XRD experiments were carried out on a Rigaku Miniflex II powder diffractometer, using $\mathrm{Cu} \mathrm{Ka}(0.15418 \mathrm{~nm})$ radiation with the $2 \theta$ angle in the range 20 to $80^{\circ}$. The Rietveld analysis of XRD data has been carried out using the Automatic Rietveld Refinement (HIGHScore Plus from PANaytical) program. The surface composition was obtained by XPS that were registered using a K-Alpha Photoelectron Spectrometer by Thermo-Scientific with an $\mathrm{Al} \mathrm{Ka}(1486.6 \mathrm{eV})$ radiation source. This analysis was done with a $5 \times 10^{-10} \mathrm{mbar}$ pressure in the chamber. Binding energy (BE) and Kinetic energy (KE) scales were adjusted by setting C1s transition at $284.6 \mathrm{eV}$. Reducibility of the catalysts was evaluated by Temperature Programmed Reduction with $\mathrm{H}_{2}\left(\mathrm{H}_{2}-\mathrm{TPR}\right)$ experiments carried out in a Pulse Chemisorb 2705 device from Micromeritics fitted with a TCD to determine changes in the outlet gas composition. $20 \mathrm{mg}$ of the sample were heated at $10^{\circ} \mathrm{C} / \mathrm{min}$ from room temperature to $900^{\circ} \mathrm{C}$ in $5 \% \mathrm{H}_{2} / \mathrm{Ar}$ atmosphere $(40$ $\left.\mathrm{ml} / \mathrm{min}, \mathrm{P}_{\mathrm{t}}=1 \mathrm{~atm}\right)$. The $\mathrm{H}_{2}$ consumption was quantified using a $\mathrm{CuO}$ reference sample supplied by Micromeritics. 
To determine the catalysts performance for soot oxidation in the highest demanding GDI exhaust conditions, Temperature Programmed Reactions $\left(10^{\circ} \mathrm{C} / \mathrm{min}\right.$ from room temperature till $900^{\circ} \mathrm{C}$, using a $100 \mathrm{ml} / \mathrm{min}$ flow of $\mathrm{He}$ to simulate the regular stoichiometric GDI operation [6]) were carried out in a TGA equipment (TGA/STDA851e/SF/1000 from Mettler Toledo) coupled to a Mass Spectrometer (Thermostar GSD301T from Pfiffer Vacuum). These experiments were run using only the perovskite catalysts (designed as $\mathrm{O}_{2}$-TPD) and soot/catalysts mixture under loose contact (1:20 ratio [9] and adding Printex $U$ as surrogated soot).

\section{Results and discussion}

\subsection{Catalysts Characterization}

Table.1 presents the nomenclature used for the perovskite catalysts and the most relevant characterization data: BET surface area (obtained by applying the BET equation to $\mathrm{N}_{2}$ adsorption data), copper content (measured by ICP-OES) and XPS data. On the one hand, the ICP-OES results reveal that almost all the copper added during the synthesis procedure is present in the catalysts, and on the other hand, the BET surface areas obtained correspond to solids with negligible porosity, as mixed oxides with perovskite structure are [10].

Table.1 Nomenclature and characterization ( $\mathrm{S}_{\mathrm{BET}}$, ICP-OES copper content, XPS) data.

\begin{tabular}{|c|c|c|c|c|c|c|}
\hline Catalyst & $\begin{array}{c}\text { Molecular } \\
\text { composition }\end{array}$ & $\begin{array}{c}\mathrm{S}_{\mathrm{BET}} \\
\left(\mathrm{m}^{2} / \mathrm{g}\right)\end{array}$ & $\begin{array}{c}\mathrm{Cu}(\mathrm{wt} \%)^{*} \\
\text { ICP }\end{array}$ & $\begin{array}{c}\mathrm{Cu} \\
/ \mathrm{Ba}+\mathrm{Fe}+\mathrm{Cu}^{*} \\
\text { XPS }\end{array}$ & $\begin{array}{c}\mathrm{Fe}(\mathrm{IV}) / \\
\mathrm{Fe}(\mathrm{III}) \\
\text { XPS }\end{array}$ & $\begin{array}{c}\mathrm{O}_{\mathrm{L}} \\
/ \mathrm{Ba}^{2} \mathrm{Fe}+\mathrm{Cu}^{*} \\
\text { XPS }\end{array}$ \\
\hline BFC0 & $\mathrm{BaFeO}_{3}$ & 4 & -- & -- & 0.9 & $1.3(1.5)$ \\
\hline BFC1 & $\mathrm{BaFe}_{0.9} \mathrm{Cu}_{0.1} \mathrm{O}_{3}$ & 1 & $2.5(2.5)$ & $0.03(0.05)$ & 1.0 & $1.7(1.5)$ \\
\hline BFC3 & $\mathrm{BaFe}_{0.7} \mathrm{Cu}_{0.3} \mathrm{O}_{3}$ & 1 & $7.0(7.7)$ & $0.09(0.15)$ & 1.0 & $1.1(1.5)$ \\
\hline BFC4 & $\mathrm{BaFe}_{0.6} \mathrm{Cu}_{0.4} \mathrm{O}_{3}$ & 3 & $9.1(9.1)$ & $0.21(0.20)$ & 1.0 & $1.1(1.5)$ \\
\hline
\end{tabular}

*Nominal value in brackets

The XRD patterns of the BFC0 and BFC1 catalysts, shown in Figure 1, reveal hexagonal perovskite structure as the main crystalline phase, even though these two catalysts also show a $\mathrm{Fe}(\mathrm{III})$ and $\mathrm{Fe}(\mathrm{IV})$ mixed-oxide with triclinic structure as a minority phase. Moreover, the decrease in the intensity of the main perovskite peak (at ca.31.5) of BFC1 catalyst indicates that copper has been satisfactorily incorporated into the perovskite structure $[13-14,17]$. In contrast, XRD patterns of BFC3 and BFC4 catalyst fit with a cubic perovskite structure. This structural modification (which has been confirmed by the Rietveld analysis shown in Figure S1 
in Supplementary information), was previously observed for other barium-based perovskites

$[13,14,17]$ and also for $\mathrm{Sn}$-doped $\mathrm{BaFeO}_{3}$ perovskites [18], seems to evidence the copper introduction into the perovskite lattice. Additionally, a $\mathrm{BaOx}-\mathrm{CuOx}$ oxide (with estimated general stoichiometry of $\mathrm{BaCuO}_{2}$ ) appears as a minority segregated phase in the XRD diffractogram of the BFC4 perovskite (the highest copper content catalyst). The presence of this minority segregated phase indicates a limit in the amount of copper incorporated into the perovskite framework $[13,14,17]$.

XPS (spectra shown in Figure S2 in Supplementary information) provides the following valuable information (included in Table 1) about the surface composition of the catalysts: (i) $\mathrm{Cu} / \mathrm{Ba}+\mathrm{Fe}+\mathrm{Cu}$ ratio, for $\mathrm{Cu}$ distribution, (ii) $\mathrm{Fe}(\mathrm{IV} / \mathrm{Fe}$ (III) ratio, for iron oxidation state, and (iii) Olattice/ $\mathrm{Ba}+\mathrm{Fe}+\mathrm{Cu}$ ratio, for lattice oxygen. Comparing the $\mathrm{Cu} / \mathrm{Cu}+\mathrm{Fe}+\mathrm{Ba}$ ratio calculated by XPS with the corresponding nominal ratio, it is confirmed that copper (which is as $\mathrm{Cu}$ (II) $[13,14,17]$ ) has been successfully incorporated into the perovskite structure since the XPS ratio is lower (for BFC1 and BFC3) or close (for BCF4) to the nominal ratio [20]. Note that the lowest difference between these two values is shown by BFC4, supporting that the limit of copper introduction has been exceeded. Thus, considering the copper content of BFC4 catalyst corresponding to the stoichiometric composition (ICP-OES data in Table 1), the exceeding copper which is not inserted into the lattice, has to be dispersed on the surface, forming other minority phases (BaOx-CuOx) identified by XRD. The deconvolution of the XPS spectra of the $\mathrm{Fe} 2 \mathrm{p}_{3 / 2}$ transition (Figure S2b in Supplementary Information), reveals the presence of two contributions [18, 21]: (i) at ca. $709 \mathrm{eV}$, corresponding to $\mathrm{Fe}(\mathrm{III})$ species, and (ii) at ca. $711 \mathrm{eV}$, suggesting the presence of $\mathrm{Fe}(\mathrm{IV})$ species. In addition, the shake-up peak at ca. $717 \mathrm{eV}$, corresponding to the satellite peak of $\mathrm{Fe}(\mathrm{III})$, supports the presence of this oxidation state. The values of $\mathrm{Fe}(\mathrm{IV}) / \mathrm{Fe}(\mathrm{III})$ ratio (all close to 1 ) indicate that both $\mathrm{Fe}(\mathrm{III})$ and $\mathrm{Fe}(\mathrm{IV})$ are present in similar proportion. An increase in the $\mathrm{Fe}(\mathrm{IV}) / \mathrm{Fe}$ (III) ratio is observed for all the copper-content catalysts, which suggests that the presence of copper promotes the oxidation of $\mathrm{Fe}(\mathrm{III})$ to $\mathrm{Fe}$ (IV) to compensate the deficiency of positive charge due to partial iron substitution by copper [10]. However, this ratio does not change proportionally to the copper content of the catalyst. This result indicates that by increasing copper content in the catalyst, new oxygen vacancies have to be generated into the perovskite structure in order to balance the positive charge deficiency. In 
the XPS spectra of the O1s transition of the catalysts (shown in Figure S2c in Supplementary Information), three main contribution areas are identified [22, 23]: i) at low BE (c.a. $528 \mathrm{eV}$ ), corresponding to lattice oxygen $\left(\mathrm{O}_{\mathrm{L}}\right)$ in metal oxides, ii) at intermediate $\mathrm{BE}$ (between 529 and $531 \mathrm{eV}$ ), assigned to adsorbed oxygen species such as, $\mathrm{O}_{2}{ }^{2-}$, surface carbonates, $\mathrm{CO}_{3}{ }^{2-}$, and/or $\mathrm{OH}^{-}$groups and iii) at high $\mathrm{BE}(\mathrm{ca} 533 \mathrm{eV})$ due to oxygen in adsorbed water. The values of $\mathrm{O}\left\llcorner/ \mathrm{Cu}+\mathrm{Fe}+\mathrm{Ba}\right.$ ratio (calculated from the peak area of $\mathrm{O}\left\llcorner, \mathrm{Fe} 2 \mathrm{p}^{3 / 2}, \mathrm{Ba} 3 \mathrm{~d}^{3 / 2}\right.$ and $\mathrm{Cu} 2 \mathrm{p}^{3 / 2}$ transitions) reveal that the BFC1 catalyst shows a higher $\mathrm{O} / \mathrm{Cu}+\mathrm{Fe}+\mathrm{Ba}$ ratio than the bare BFC0 perovskite, which means a lower amount of surface oxygen vacancies. This founding is related to the higher amount of $\mathrm{Fe}(\mathrm{IV})$ in this perovskite and it seems to prove that in BFC1 the oxidation of $\mathrm{Fe}(\mathrm{III})$ to $\mathrm{Fe}(\mathrm{IV})$ takes place to compensate the charge deficiency. For BFC3 and BFC4 catalysts, the lower $\mathrm{O} \downarrow / \mathrm{Cu}+\mathrm{Fe}+\mathrm{Ba}$ ratio respect to the nominal value, confirms the generation of oxygen vacancies due to partial iron substitution by copper.

To study the different oxygen species present in the catalysts, the $\mathrm{O}_{2}-$ TPD profiles shown in Figure $1 \mathrm{~b}$ were obtained. They can be split into three regions $[13,25,26]$ : i) below $400^{\circ} \mathrm{C}$, denoted as $\alpha$ - oxygen, which corresponds to weakly chemisorbed oxygen upon surface-oxygen vacancies, ii) between 400 and $700^{\circ} \mathrm{C}$ designed as $\alpha^{\prime}$ oxygen, and ascribed to near-surface oxygen associated to lattice defects such as dislocations and grains frontiers, and iii) at $T>$ $700^{\circ} \mathrm{C}$, named $\beta$ oxygen and generally associated with the lattice oxygen and with the reduction of $\mathrm{B}$ cation $(\mathrm{Fe}(\mathrm{III})$ or $\mathrm{Fe}(\mathrm{IV}))$ in the perovskite framework. The $\mathrm{O}_{2}-\mathrm{TPD}$ profiles reveal that $\alpha$ and $\alpha^{\prime}$ oxygen is mainly evolved by most of the $\mathrm{BaFe}_{1-x} \mathrm{Cu}_{x} \mathrm{O}_{3}$ catalysts $[7,8]$. BFC0, BFC3 and BFC4 show the higher $\alpha$-oxygen signals than BFC1, and for hence, the higher amount of surface-oxygen vacancies, in agreement with the XPS results (lower $\mathrm{O} / \mathrm{Cu}+\mathrm{Fe}+\mathrm{Ba}$ ratio). Regarding $\alpha^{\prime}$-oxygen, BFC1 shows the higher signal, evidencing the large structure distortion (as showed by XRD) promoted by a small $\mathrm{Cu}$ incorporation. The total amount of $\mathrm{O}_{2}$, calculated from the area under the $\mathrm{O}_{2}$ profiles, decreases as copper content increases: $424 \mu \mathrm{mol} / \mathrm{g}$ cat $($ BFC0 $)>333 \mu \mathrm{mol} / \mathrm{g}$ cat $($ BFC1) $>282 \mu \mathrm{mol} / \mathrm{g}$ cat $($ BFC3 $)>275 \mu \mathrm{mol} / \mathrm{g}$ cat $($ BFC4) $)$. Thus, as it was previously observed in the literature [18], the addition of copper seems to stabilize the oxygen bonded to Feand leads to lower evolution of oxygen during $\mathrm{O}_{2}$-TPD. Finally, note that for BFC4, (and more subtly for BFC3) even though the total amount of desorbed $\mathrm{O}_{2}$ is lower, an 
increase in the $\beta$-oxygen has been detected, which is probably related with the structural

change and the presence of the $\mathrm{BaOx}-\mathrm{CuOx}$ mixed-oxide identified by XRD.

\subsection{Catalytic activity}

The $\mathrm{CO}_{2}$ production profiles (negligible amount of $\mathrm{CO}$ as soot oxidation product was evolved) during the soot oxidation experiments carried out in inert atmosphere (the highest demanding GDI exhaust conditions) are featured in Figure 2a. Note that all catalysts are active for oxidizing soot in the absence of oxygen at temperatures higher than ca. $550^{\circ} \mathrm{C}$ and also, that the amount of $\mathrm{CO}_{2}$ increases with the copper content. The $\mathrm{CO}_{2}$ profile corresponding to uncatalyzed soot oxidation has not been included as $\mathrm{CO}_{2}$ is not detected (reaction atmosphere composed by $100 \% \mathrm{He})$. . It is worth mentioning that $\mathrm{CO}_{2}$ signal in Figure $2 \mathrm{a}$ only comes from soot oxidation, as the $\mathrm{CO}_{2}$ signal corresponding to surface species decomposition (Figure S3 in Supplementary Information) has been subtracted.

Considering that soot removal is an oxidation reaction and oxygen (or another oxidizing agent) is not present in the reaction atmosphere, perovskite catalysts have to supply the oxygen required for soot oxidation to $\mathrm{CO}_{2}$. Figure $2 \mathrm{~b}$ features the $\mathrm{O}_{2}$ profiles evolved during soot oxidation experiments. From the comparison of these profiles with the $\mathrm{O}_{2}$-TPD profiles (Figure 1b), no clear differences are observed at low temperature, however, above $750^{\circ} \mathrm{C}$ oxygen is not identified in Figure $2 \mathrm{~b}$. As this oxygen consumption fits with the temperature range when $\mathrm{CO}_{2}$ is evolved due to soot removal, it can be concluded that the $\mathrm{O}_{2}$ released at high temperature, by $\mathrm{BaFe}_{1-\mathrm{x}} \mathrm{Cu}_{x} \mathrm{O}_{3}$ catalysts ( $\beta$-oxygen) is being used for soot oxidation reaction generating $\mathrm{CO}_{2}$ as main oxidation product. Based on this assumption, the amount of $\beta$-oxygen has been estimated by subtracting the amount of $\mathrm{O}_{2}$ not consumed during soot oxidation (that is the $\mathrm{O}_{2}$ evolved shown in Figure $2 b$ ) from the total amount of $\mathrm{O}_{2}$ released by the catalysts featured in Figure $1 b$.. The data confirm that BFC4 evolves the largest amount of $\beta$-oxygen among the iron containing catalysts $(70 \mu \mathrm{mol} / \mathrm{g}$ cat $(\mathrm{BFC} 1)>31 \mu \mathrm{mol} / \mathrm{g}$ cat $(\mathrm{BFC} 3)>118 \mu \mathrm{mol} / \mathrm{g}$ cat $(\mathrm{BFC} 4))$. According to the weight loss curves (registered by TGA) corresponding to soot oxidation experiments, the percentage of soot conversion along the whole experiment has been calculated for all the catalysts. This value increases with the copper content from $29 \%$ for BFC0, to $44 \%$ for BFC1, $69 \%$ for BFC3 and $94 \%$ for BFC4. These results agree with that reported for 
copper-supported ceria-zirconia catalysts for soot oxidation in GDI conditions [9]. The highest soot conversion shown by the highest copper content catalysts (BFC4) seems to be related with their largest amount of $\beta$-oxygen evolved, as well as with the presence of a high amount of surface copper species (as $\mathrm{BaOx}-\mathrm{CuOx}$ oxide) which catalyze the soot oxidation reaction $[9,27-$ 30]. As the performance of BFC4 is hold during a second cycle of oxidation reaction in TPR conditions (cooling down to room temperature in synthetic air after the first TPR cycle, following by addition of an identical amount of surrogated soot to carry out the second cycle), the catalytic role seems to be probed.

From these preliminary results, it can be concluded that $\mathrm{BaFe}_{1-\mathrm{x}} \mathrm{Cu}_{x} \mathrm{O}_{3}$ perovskites catalyze soot oxidation in GDI exhaust conditions [7,9] and, for hence, could be used as catalysts for GPF. Copper content has a key role on the performance of the $\mathrm{BaFe}_{1-\mathrm{x}} \mathrm{Cu}_{x} \mathrm{O}_{3}$ catalyst for soot oxidation, which is in agreement with previous reports focused on diesel soot removal [13-17, 27-30] and with that reported for copper-supported ceria-zirconia catalysts for soot oxidation in GDSI conditions [9]. Thus, the highest soot conversion shown by BFC4 seems to be related not only with the largest amount of $\beta$-oxygen evolved by this catalyst, but also with the presence of a high amount of surface copper species (as $\mathrm{BaOx}-\mathrm{CuOx}$ oxide) which catalyze the soot oxidation reaction $[9,27-30]$. In order to complete this study, a deeper analysis of the activity and stability of catalysts, in isothermal reaction conditions, as well as under diesel conditions for comparative purpose, is now under developing.

\section{Conclusions}

From the results presented and discussed, the following conclusion can be drawn:

* Partial substitution of iron by copper in the lattice of $\mathrm{a} \mathrm{BaFeO}_{3}$ mixed-oxide perovskite generates a distortion of the hexagonal perovskite structure for the lowest copper content catalyst (BFC1), and a change to cubic structure for the higher copper content catalysts (BFC3 and BFC4).

${ }^{*}$ Certain copper incorporation limitation is found for the highest copper content catalyst (BFC4) which causes the presence of $\mathrm{BaOx}-\mathrm{CuOx}$ as minority segregated phase.

* The positive charge deficiency generated due to partial substitution of iron by copper in $\mathrm{BaFe}_{1}$ ${ }_{x} \mathrm{Cu}_{\times} \mathrm{O}_{3}$ catalysts is balanced by an increase in $\mathrm{Fe}(\mathrm{IV}) / \mathrm{Fe}(\mathrm{III})$ ratio respect to bare perovskite for 
the lowest copper content catalyst, and, by the generation of new oxygen vacancies/defects for the higher copper content catalysts (BFC3 and BFC4).

* The $\mathrm{BaFe}_{1-\mathrm{x}} \mathrm{Cu}_{x} \mathrm{O}_{3}$ perovskites are active for soot oxidation in the highest demanding GDI exhaust conditions (regular stoichiometric GDI operation, i. e.0\% $\mathrm{O}_{2}$ ) and, consequently, they could be used as catalysts for GPF. The highest soot conversion shown by BFC4 is related to its largest amount of $\beta$-oxygen evolved, as well as, to the presence of high amount of surface copper species (as $\mathrm{BaOx}-\mathrm{CuOx}$ oxide) which are active for soot oxidation removal.

\section{Acknowledgements.}

The authors thank Generalitat Valenciana (PROMETEO/2018/076), Spanish Government (MINECO project CTQ2015-64801-R) and UE (FEDER Founding) for the financial support. V. Torregrosa- Rivero thanks the Generalitat Valenciana for her Ph.D. grant (ACIF 2017/221).

\section{References}

[1] T.V. Johnson SAE Tech. Pap. (2014), 2014-01-1491.

[2] A. Mamakos, N. Steininger, G. Martini, P. Dilara, Y. Drossinos Atmost. Environ. 77 (2013) 16-23.

[3] B. Guan, R. Zhan, H. Lin, Z. Huang, J. Environ. Manag. 154 (2015) 225-248.

[4] T.V. Johnson SAE Tech. Pap. (2012), 2012-01-0368.

[5] C.H. Kim, M. Schmid, S.J. Schmieg, J.L. Tan, W. Li SAE Tech. Pap. 2011 (2011), -01-1134.

[6] T. Boger, D. Rose, P. Nicolin, N. Gunasekaran, T. Glasson Emiss. Control. Sci. Technol. 1 (2015), 49-63.

[7] W.Y. Hernández, M.N. Tsampas, C. Zhao, A. Bosselet, P. Vernoux Catal. Today 258 (2015) 525-534.

[8] W.Y. Hernández, D. López-González, S. Ntais, , C. Zhao, A. Boréave, P. Vernoux Appl. Catal. B 226 (2018), 202-212.

[9] J. Giménez- Mañogil, S. Quiles-Díaz, N. Guillén-Hurtado, A, García-García Top. Cat. 60 (2107) 2-12.

[10] M.A. Peña, J.L.G. Fierro Chem. Rev. 101 (2001) 1981- 2018.

[11] B. Ura, J. Trawczynski, A. Kotarba, W. Bieniasz, M.J. Illán-Gómez, A. Bueno-López, F.E. López-Suárez, Appl. Cat. B 101 (2011) 169-175.

[12] S.K. Mgarajuan, S. Rayalu, M. Nishibori, Y. Teraoka, N. Labhsetwa ACS Catal. 5 (2015) 301-309.

[13] V. Torregrosa-Rivero, V. Albaladejo-Fuentes, M. S. Sánchez- Adsuar, M. J. Illán-Gómez RSC Adv. 7 (2017), 35228- 3538. 
[14] . Albaladejo-Fuentes, F. E. López-Suárez, M. S. Sánchez-Adsuar, M. J. Illán-Gómez, Appl. Catal. A 519 (2016) 7-15.

[15] F. E. López-Suárez, S. Parres-Esclapez, A. Bueno-López, M. J. Illán-Gómez, B. Ura , J. Trawczynski Appl. Catal. B 93 ( 2009) 82-89.

[16] F. E. López-Suárez, A. Bueno-López, M. J. Illán-Gómez, J. Trawczynski Appl. Catal. A. 485 (2014) 214-221.

[17] V. Albaladejo-Fuentes, F. E. López-Suárez, M. S. Sánchez-Adsuar, M. J. Illán-Gómez Appl. Catal. A. 488 (2014) 189-199.

[18] C. Huang, Y. Zhu, X. Wang, X. Liu, J. Wang, T. Zhang J.Catal. 347 (2017) 9-20.

[19] J. Ghijsen, L.H. Tjeng, J. van Elp, H. Eskes, J. Wesrterink, G.A. Sawatzy, M.T. CzyzykPhys. Review B 38 (1988) 11322-11330.

[20] X. Chen, L. Huang, Y. Wei, H. Wang J. Membr. Sci 368 (2011) 159-164.

[21] Y. Wu, C. Cordier, E. Berrier, N. Nuns, C. Dujardin, P. Granger Appl. Catal. B 140-141 (2013) 151-163.

[22] Benoit R., Centre de Recherche sur la Matière Divisée - CNRS. www.lasurface.com (2013).

[23] ] L. Cadus, N. Merino, B. Barbero, P. Eloy Appl Surf Sci 253 (2006) 1489-1493.

[24] H. Xian, X. Zhang, X. Li, L. Li, H. Zou, M. Meng, Q. Li, Y. tan, N, Tsubak J. Phys. Chem. C 114 (2019) 11844-11852.

[25] N.A. Merino, B.P. Barbero, P. Grange, L.E. Cadús J. Catal, 231 (2005) 232-244.

[26] J.A. Onrubia, B. Pereda-Ayo, U. De-La-Torre, J.R. González - Velasco Appl. Catal. B 213 (2017) 198-210.

[27] Q. Liang, X. Wu, D. Weng, Z. Lu Catal. Comm. 9 (2008) 202-206.

[28] F. E. López-Suárez, A. Bueno-López, M. J. Illán-Gómez Appl. Catal. B 84 (2008) 651-658.

[29] Y. Wang, J. Wang, H. Chen, M. Yao, Y. Li, Chem. Eng. Sci. 135 (2015) 294-300.

[30] T. Andana. M. Piumetti, S. Bensaid, L. Veyre, c. Thieuleux, N. Russo, D. Fino, E. A. Quaderlli, R. Pirone Appl. Catal. B 216 (2017) 41-58. 
Fig.1 Catalysts characterization: a) XRD patterns, b) $\mathrm{O}_{2}$-TPD profiles

a)

- $\mathrm{BaFeO}_{3}$ (hexagonal)

$+\mathrm{BaFeO}_{3}$ (triclinic)

- $\mathrm{BaFeO}_{3}$ (cubic)

- $\mathrm{BaCuO}_{2}$
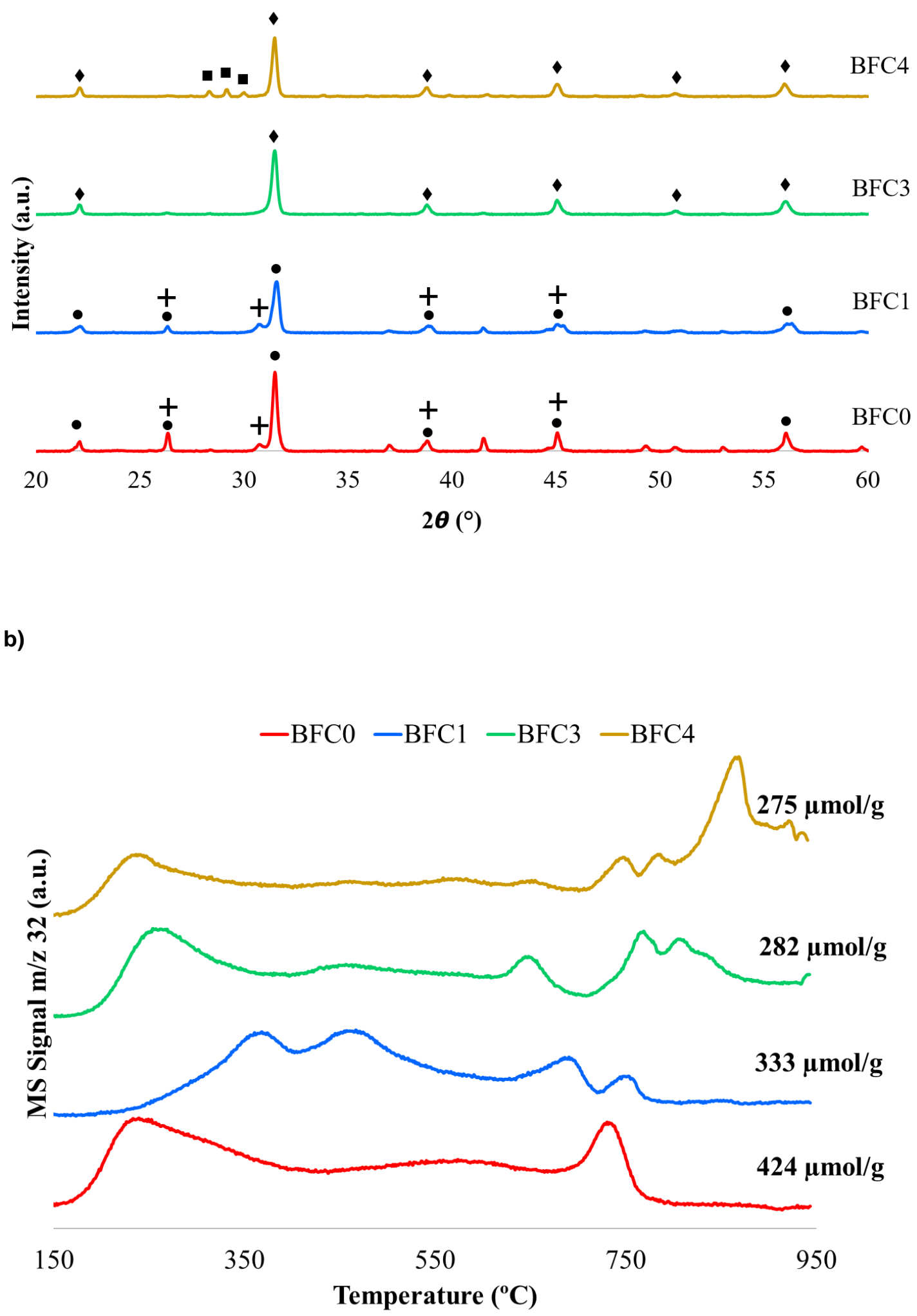
Fig.2. Soot oxidation in He: a) $\mathrm{CO}_{2}$ evolution profiles and b) $\mathrm{O}_{2}$ evolution profiles.

a)

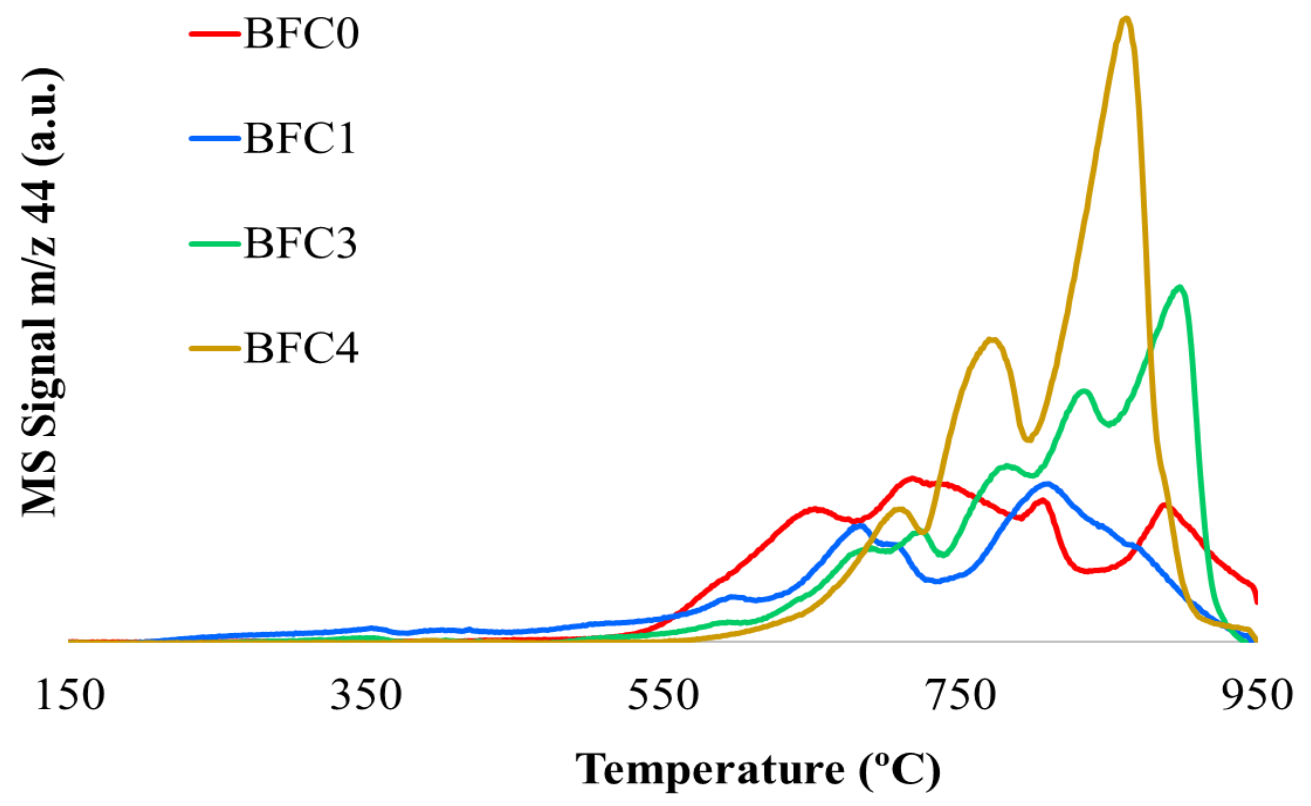

b)

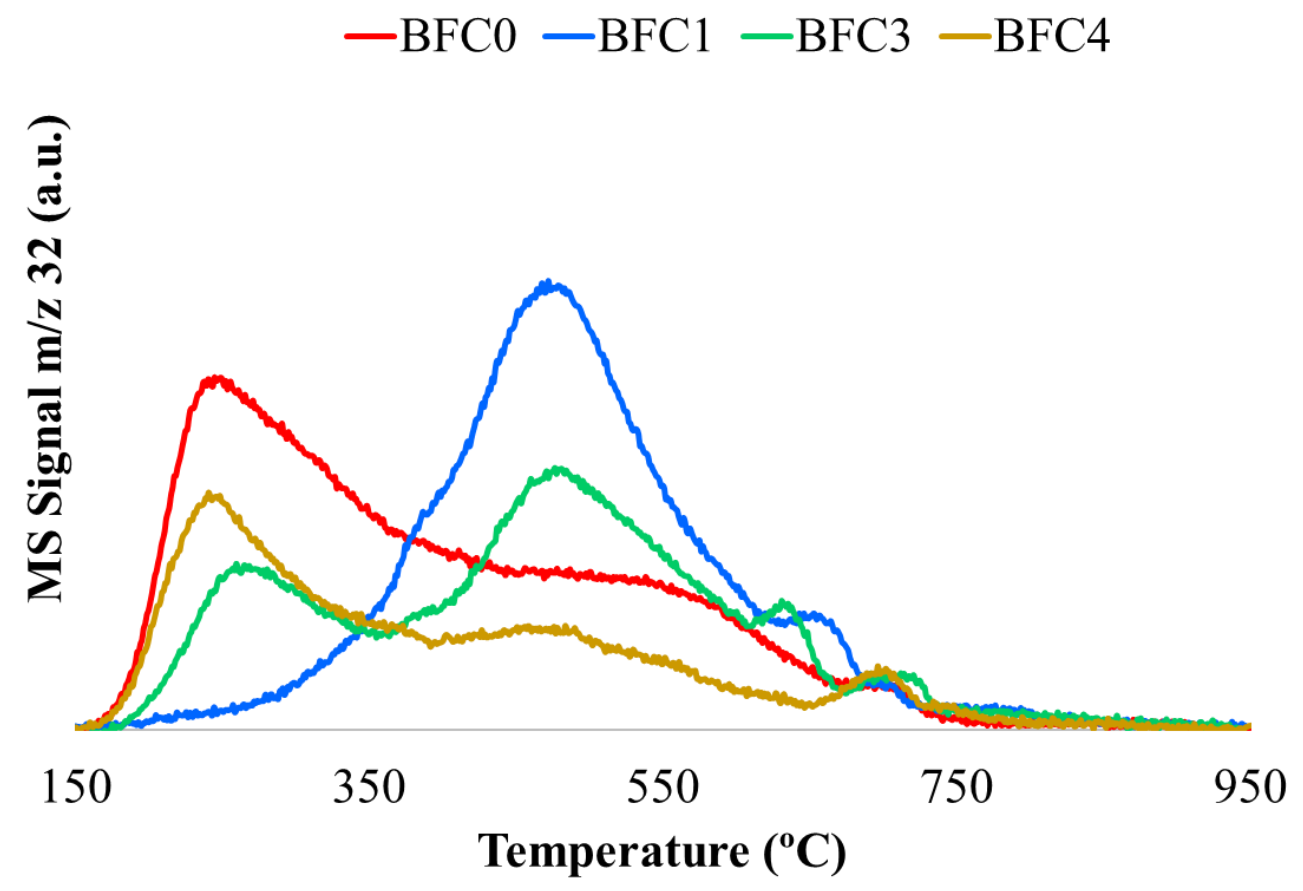




\section{Supplementary Information}

$\mathrm{BaFe}_{1-\mathrm{x}} \mathrm{Cu}_{\mathrm{x}} \mathrm{O}_{3}$ perovskites as soot oxidation catalysts for Gasoline Particulate Filters (GPF)

C. Moreno-Marcos, V. Torregrosa-Rivero, V. Albaladejo-Fuentes, M.S. Sánchez-Adsuar, M.J. Illán-Gómez*

Departamento de Química Inorgánica, Facultad de Ciencias, Universidad de Alicante, Ap. 99, Alicante, E-03080.

\section{*illan@ua.es}

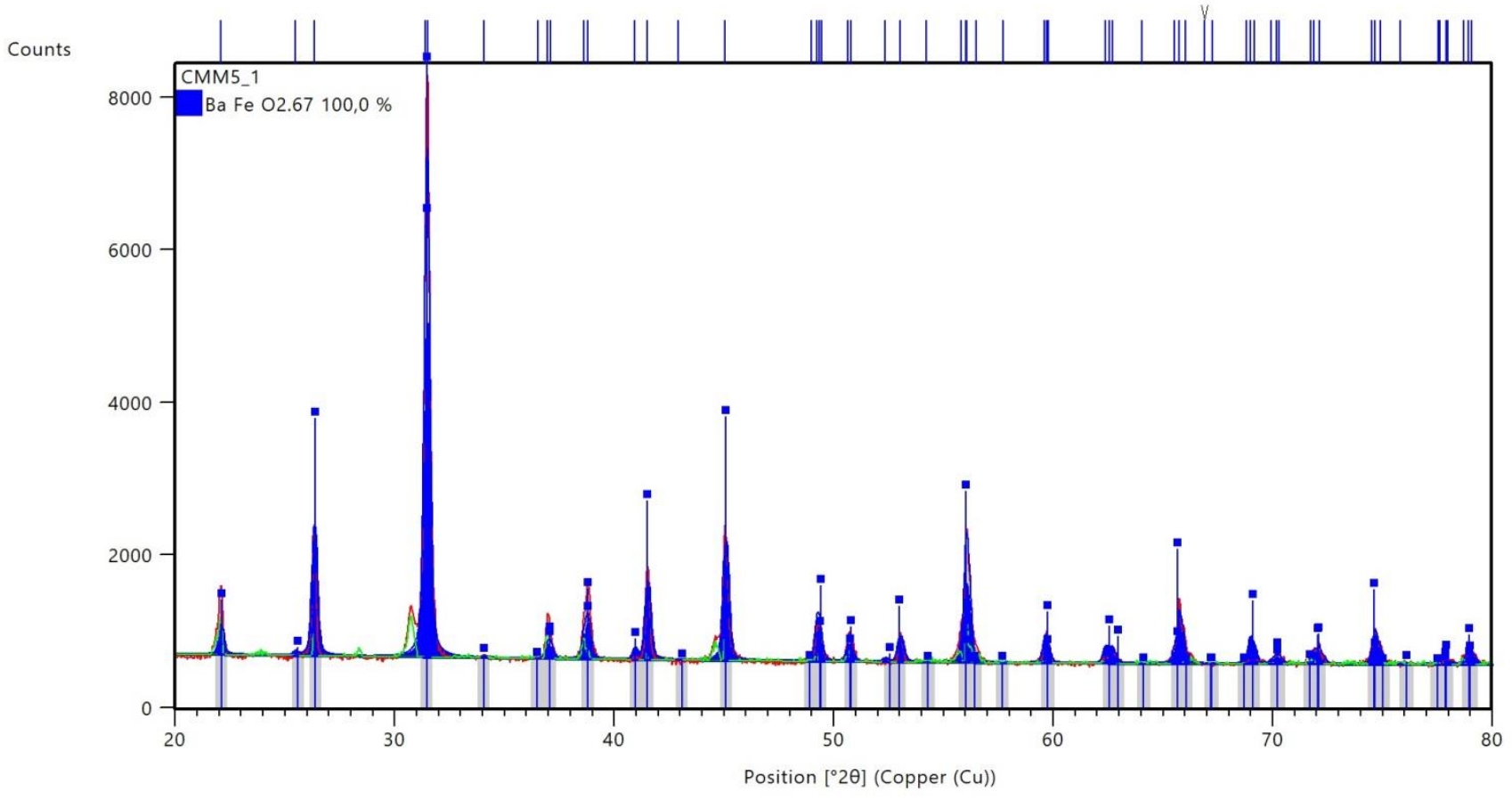

Figure S1 a) Rietveld analysis for BFCO: in red the original XRD pattern, in blue the Rietveld simulation corresponding to hexagonal perovskite structure and in green the residual data corresponding to triclinic structure (minority phase not included in the analysis). 
Counts

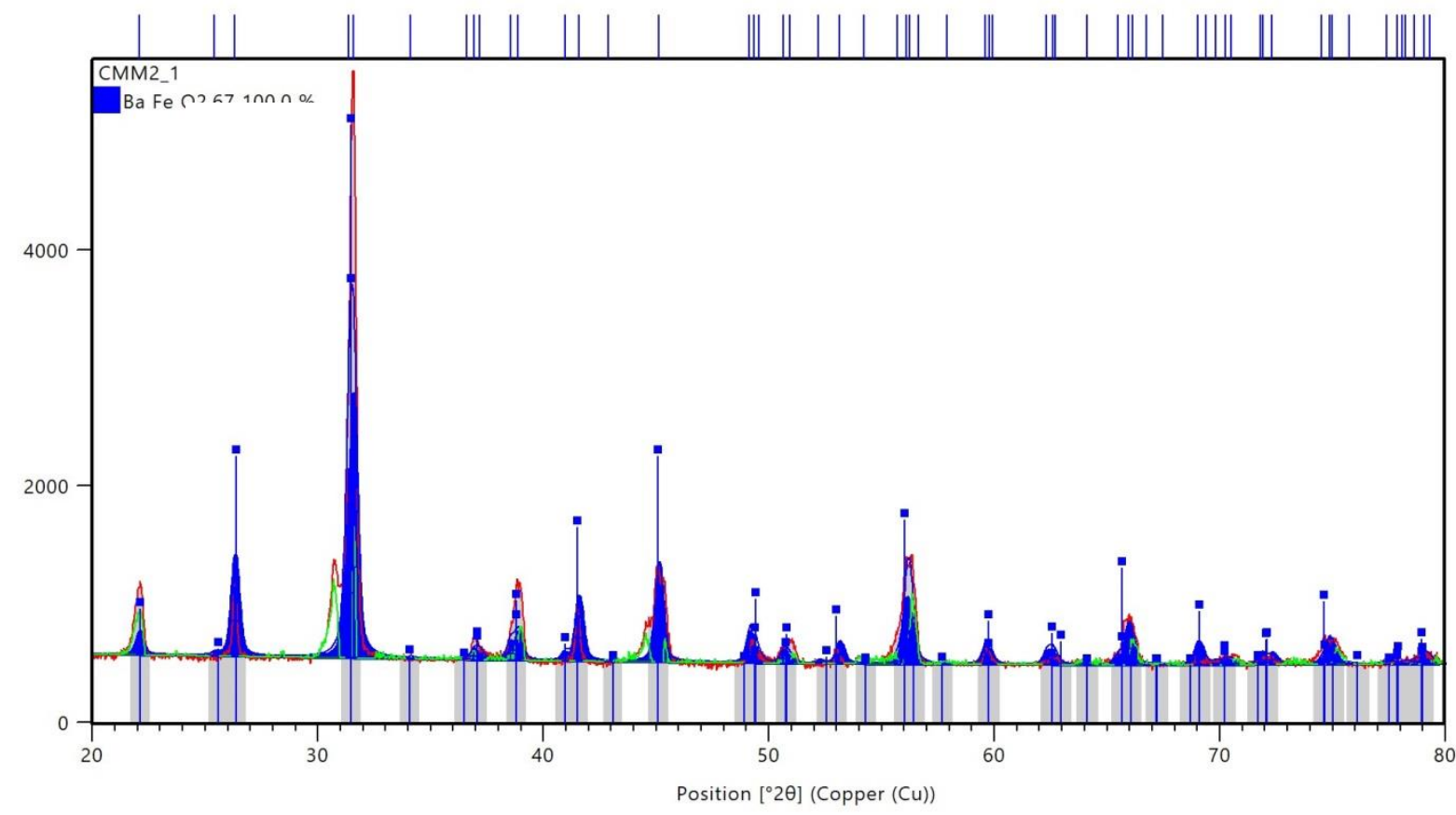

Figure S1 b) Rietveld analysis for BFC1: in red the original XRD pattern, in blue the Rietveld simulation corresponding to hexagonal perovskite structure and in green the residual data corresponding to triclinic structure (minority phase not included in the analysis).

Counts

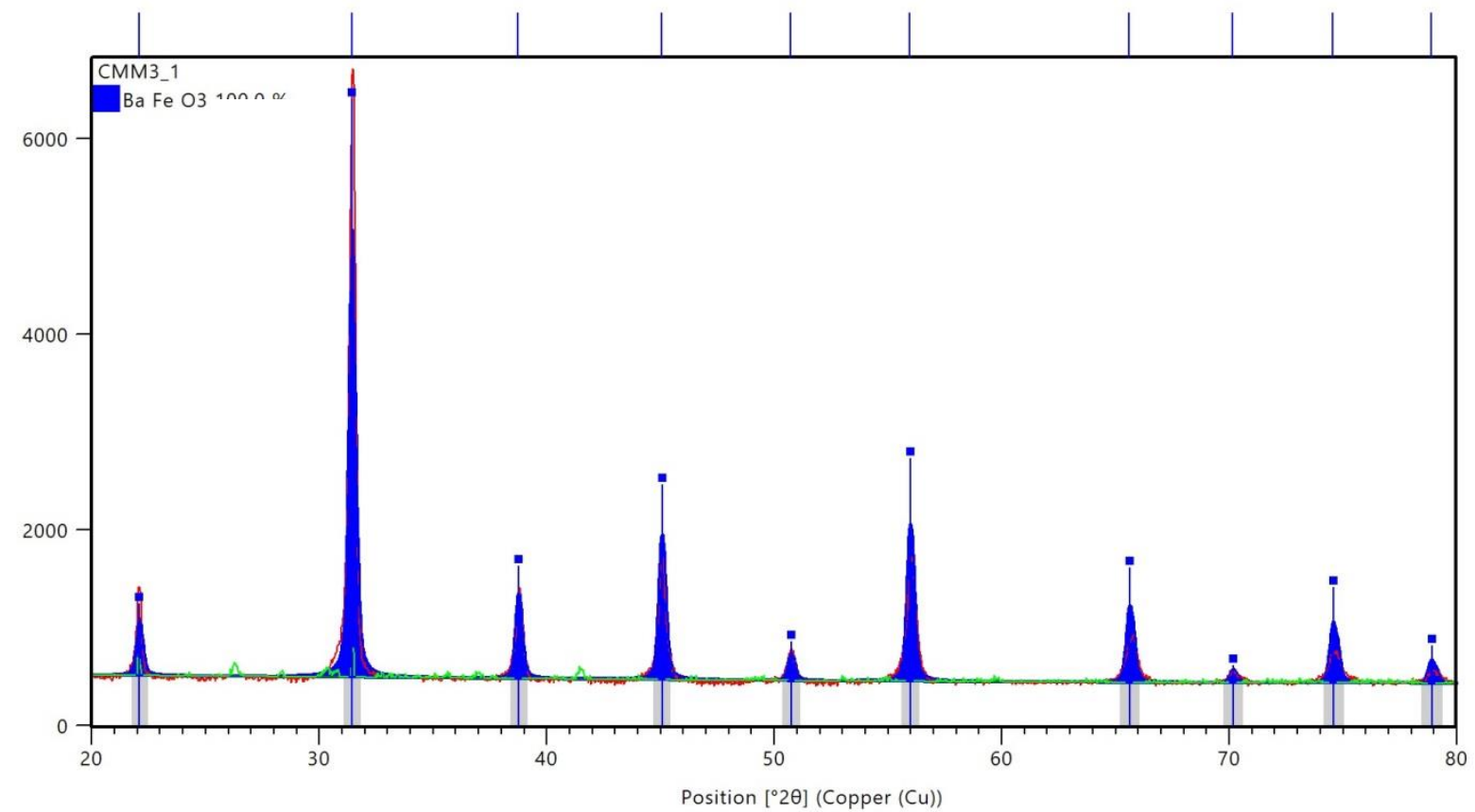

Figure S1 c) Rietveld analysis for BFC3: in red the original XRD pattern, in blue the Rietveld simulation corresponding to cubic perovskite structure and in green the residual data corresponding to $\mathrm{BaCuO}_{2}$ oxide (minority phase not included in the analysis). 


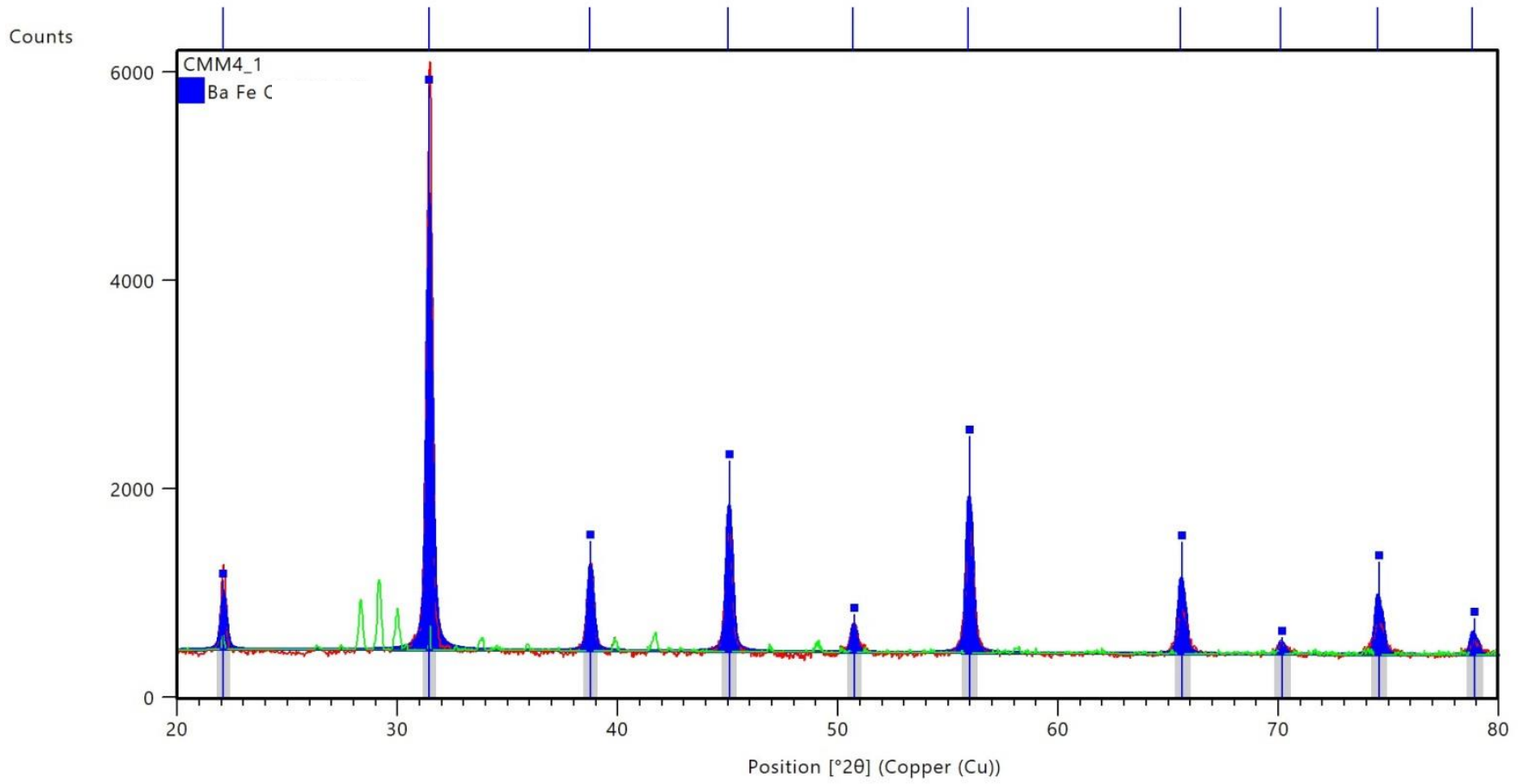

Figure S1 d) Rietveld analysis for BFC4: in red the original XRD pattern, in blue the Rietveld simulation corresponding to cubic perovskite structure and in green the residual data corresponding to $\mathrm{BaCuO}_{2}$ oxide (minority phase not included in the analysis). 
Figure S2. a). XPS spectra for Cu2 $p^{3 / 2}$ transition

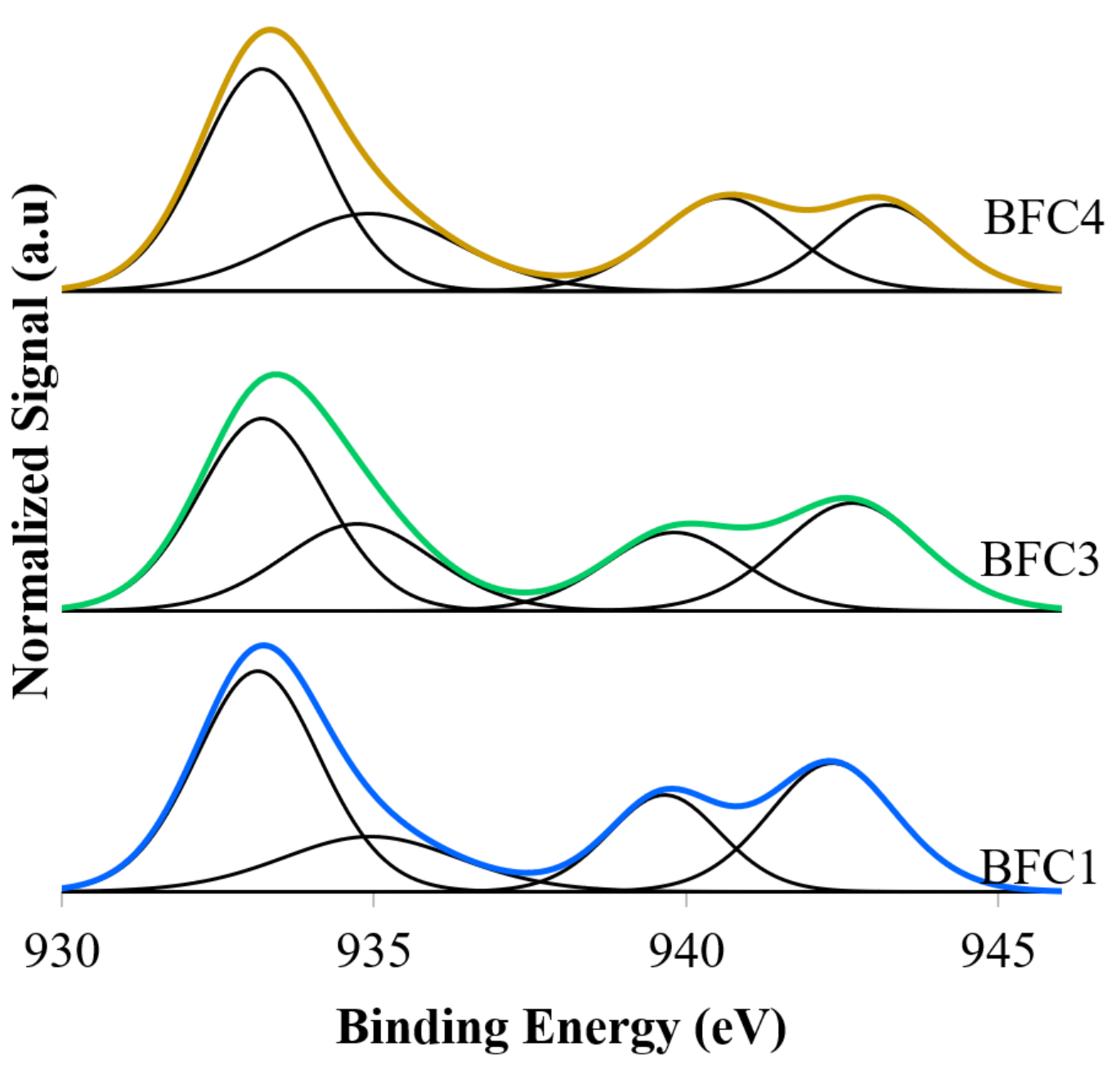


Figure S2. b). XPS spectra for Fe2 $p^{3 / 2}$ transition

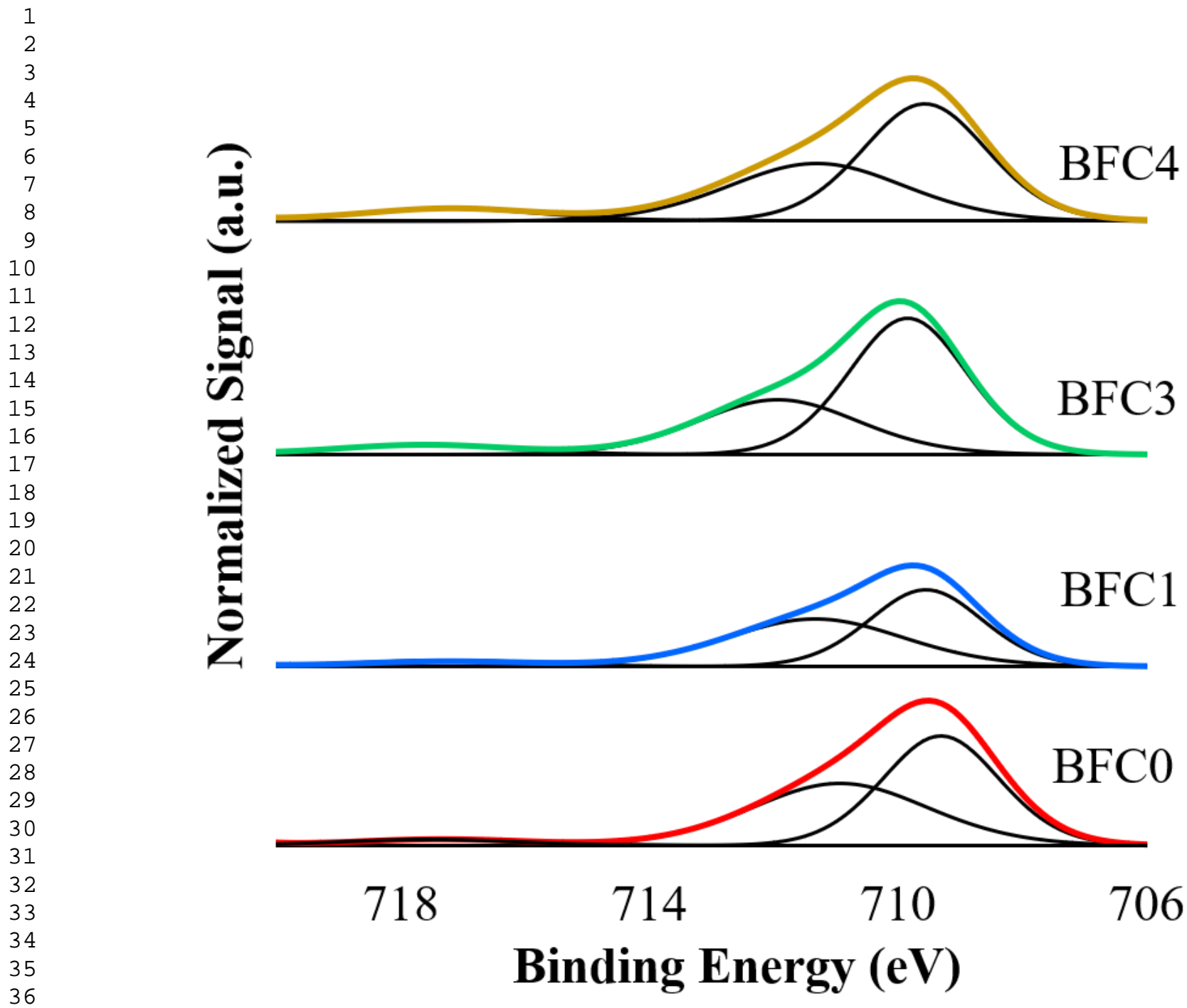


Figure S2. c). XPS spectra for 0 1s transition
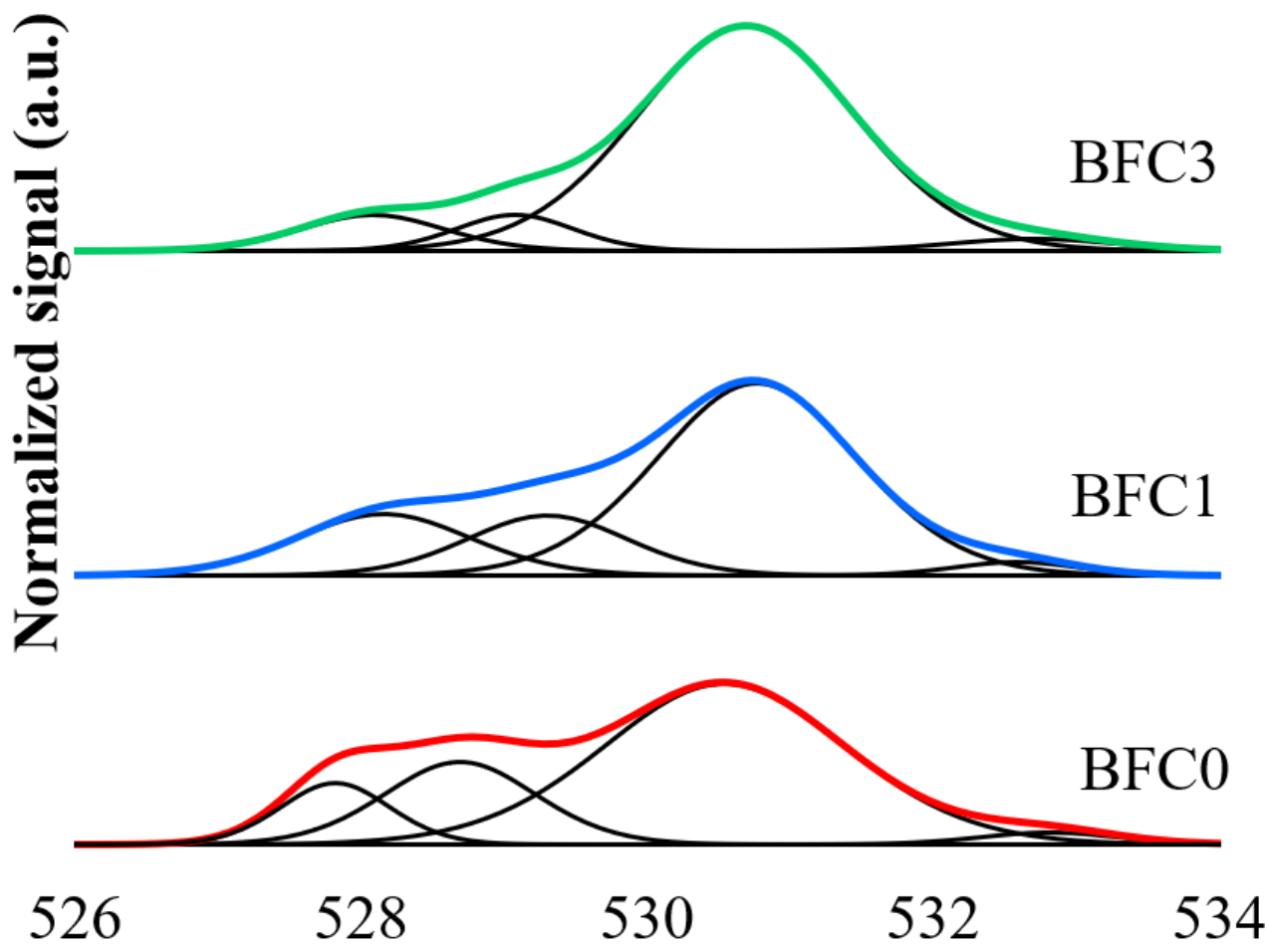

Binding Energy (eV) 
Figure $\mathrm{S3} \mathrm{CO}_{2}$ evolution during $\mathrm{O}_{2}-\mathrm{TPD}$

1

2

3

4

5

6

7

8

9

10

11

12

13

14

15

16

17

18

19

20

21

22

23

24

25

26

27

28

29

30

31

32

33

34

35

36

37

38

39

40

41

42

43

44

45

46

47

48

49

50

51

52

53

54

55

56

57

58

59

60

61

62

63

64

65

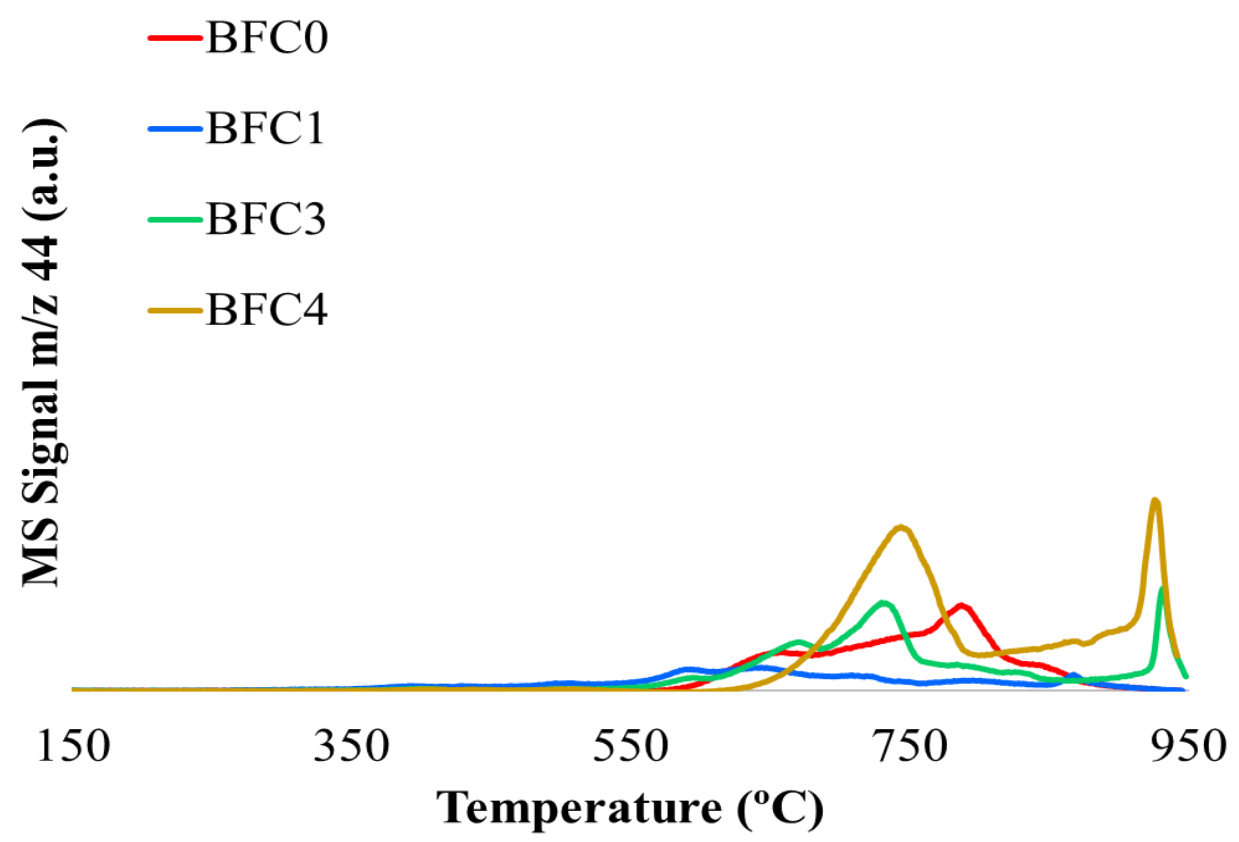




\section{Answer to Reviewer \#1}

The paper deals with a series of BaFe1-xCuxO3 catalysts ( $x=0,0.1,0.3$ and 0.4$)$ that have been synthesized, characterized and used for soot oxidation in Gasoline Diesel Injection (GDI) exhaust conditions.

The manuscript is well write and organized, the data are of good quality and the results well described and correlated with the morphological characterization.

However, minor point should be clarified before publication.

The authors kindly thank the reviewer comments that have been considered in order to improve the quality of the manuscript. Below, the authors answer to each reviewer comment:

1-Why the Authors define the flow of He as the correct way to simulate the regular stoichiometric GDI operation?

In the reference 6 (T. Boger et al. "Oxidation of Soot (Printex U) in Particulate Filters Operated on Gasoline Engines"), it is indicated that essentially no $\mathrm{NO}_{2}$ and $\mathrm{O}_{2}$ are available for soot oxidation under normal stoichiometric GDI operation. Consequently, in the manuscript the highest demanding GDI condition, that is $0 \% \mathrm{O}_{2}$, has been selected in order to be in the worst possible conditions. Note that also the selected surrogated soot (Printex $\mathrm{U})$ represents the least reactive fraction of particulate matter.

2-The distortion of hexagonal structure and/or the transformation into the cubic structure have been confirmed by a Rietveld analysis?

The results of the Rietveld analysis confirm the structural modification detected by XRD. A sentence indicating this fact has been added to the manuscript:

"This structural modification (which has been confirmed by the Rietveld analysis shown in Figure S1 in Supplementary information), was previously observed for other barium-based perovskites $[13,14,17]$ and also for $\mathrm{Sn}$-doped $\mathrm{BaFeO}_{3}$ perovskites [18], seems to evidence the copper introduction into the perovskite lattice..",

3-Does the Cu segregation up to a certain load of $\mathrm{Cu}$ influence the catalytic activity?

As it is discussed in the Catalytic activity section, the presence of copper species as segregated phase (BaOx-CuOx) seems to justify that BFC4 presents the highest activity as copper oxides are a well-known catalysts for oxidation reaction. However, it is worth indicating that the copper species segregated in the BFCX catalyst are ascribed to a BaOxCuOx mixed oxide, not to $\mathrm{CuO}$, as it is mentioned in the manuscript: 
"A BaOx-CuOx oxide (with estimated general stoichiometry of $\mathrm{BaCuO}_{2}$ ) appears as a minority segregated phase in the XRD diffractogram of the BFC4 perovskite (the highest copper content catalyst)."

4-The comparison with the uncatalyzed soot oxidation and with other traditional catalytic materials used in this process could be useful to valorize the reported results.

The comparison with both uncatalyzed and other traditional catalytic materials has been included in the revised version. The following sentences have been added:

"The $\mathrm{CO}_{2}$ profile corresponding to uncatalyzed soot oxidation has not been included as $\mathrm{CO}_{2}$ is not detected (reaction atmosphere composed by $100 \% \mathrm{He}$ )."

"This value increases with the copper content from 29\% for BFCO, to 44\% for BFC1, 69\% for BFC3 and 94\% for BFC4. These results agree with that reported for copper-supported Ceriazirconia catalysts for soot oxidation in GDI conditions [9]."

"Copper content has a key role on the performance of the $\mathrm{BaFe}_{1-x} \mathrm{Cu}_{x} \mathrm{O}_{3}$ catalyst for soot oxidation, which is in agreement with previous reports focused on diesel soot removal [1317, 27-30] and with that reported for copper-supported Ceria-zirconia catalysts for soot oxidation in GDSI conditions [9]." 


\section{Answer to Reviewer \#2}

The authors synthesized composite oxides of $\mathrm{Cu}$, Fe and Ba by a citrate sol-gel method, and investigated the properties and activities of the compounds obtained by their composition ratio. It is interesting to analyze the relationship between characteristics of the obtained compounds and their activity. However, the discussion of the data obtained is insufficient. Therefore, the additional information and discussion should be provided for the readers. Detailed comments are as follows:

The authors kindly thank the reviewer comments that have been considered in order to improve the quality of the manuscript. Below, the authors answer to each reviewer comment:

General comments:

1) In Figure 1(b), O2-TPD measurements were performed and oxygens were ascribed to three species at each temperature range. In addition, b-oxygen was effective to oxidize soot in the next section 3.2. Therefore, I think that not only the total amount of desorbed oxygen but also the amount of 8-oxygen should be compared with the catalytic activity.

We totally agree with reviewer, in fact, we point out the relationship between catalytic activity for soot oxidation and amount of $\beta$-oxygen. Attending the comment of the reviewer, an $d$ in order to show more clearly this fact, we estimated the amount of this type of oxygen by subtracting the amount of $\mathrm{O}_{2}$ not consumed during soot oxidation (that is the $\mathrm{O}_{2}$ evolved shown in Figure $2 \mathrm{~b}$ ) from the total amount of $\mathrm{O}_{2}$ released by the catalysts featured in Figure 1b..The data confirm that BFC4 evolves the largest amount of $\beta$-oxygen among the iron containing catalysts (70 $3 \mathrm{~mol} / \mathrm{g}$ cat (BFC1) $>31$ ? $\mathrm{mol} / \mathrm{g}$ cat (BFC3) > $118 \mathrm{~mol} / \mathrm{g}$ cat (BFC4)). In this sense, the following paragraph has been added:

"Based on this assumption, the amount of $\beta$ oxygen has been estimated by subtracting the amount of $\mathrm{O}_{2}$ not consumed during soot oxidation (that is the $\mathrm{O}_{2}$ evolved shown in Figure 2b) from the total amount of $\mathrm{O}_{2}$ released by the catalysts featured in Figure $1 \mathrm{~b}$.. The data confirm that BFC4 evolves the largest amount of $\beta$-oxygen among the iron containing catalysts (70 [mol/g cat (BFC1) > 31 ? $\mathrm{mol} / \mathrm{g}$ cat (BFC3) > 118 [ ]mol/g cat (BFC4))."

2) Have you evaluated the activity of Ba-Cu mixed-oxide? It is desirable to list iron-free catalyst synthesized in the same way as a reference.

In the manuscript we incorrectly denominate "Ba-Cu mixed oxide" to the mixture of $\mathrm{BaOx}$ and CuOx oxide that we have identified by a XRD peak which, tentatively, correspond to a general stoichiometry $\mathrm{BaCuO}_{2}$ that is an ideal composition corresponding to $\mathrm{BaO}$ and $\mathrm{CuO}$ oxide. To solve this issue, we have modified the denomination along the text of the revised version of the manuscript.

In relation to the second demand, the authors have checked the reproducibility of the BFC4 catalyst by this synthesis route and $\mathrm{BaCuO}_{2}$ phase is always identified as segregated phase in 
this catalyst by XRD. This result allows suggesting that in this catalyst the copper content exceed the metal amount that can be incorporated into the perovskite $\mathrm{BaFeO} 3$ lattice. Additionally, BaOx-CuOx mixed oxide was synthesized by means of this sol-gel route in order to prepare a reference material. Unfortunately, the catalyst obtained by this method is a highly heterogeneous material ( $\mathrm{BaCuO2}-\mathrm{CuO}-\mathrm{BaO})$ that could not be tested for soot oxidation.

3) In this paper, BaFe1-xCuxO3 oxidized soot by using the oxygen in the catalyst. Can these compounds work as a catalyst? Does the catalyst cooled in air to room temperature after activity evaluation show the same activity? If these compounds do not work as a catalyst, I hope your suggestion for countermeasure against them.

In order to probe the catalytic role of perovskite, two consecutive TPR experiments (with a cooling down in air between first and second one) have been successfully carried out. To illustrate this issue, the following sentence has been included in the revised version of the manuscript:

"As the performance of BFC4 is hold during a second cycle of oxidation reaction in TPR conditions (cooling down to room temperature in synthetic air after the first TPR cycle, following by addition of an identical amount of surrogated soot to carry out the second cycle), the catalytic role seems to be probed."

4) Please propose your future plans. Oxidize in lower temperature, improve the heat durability, etc.

The following paragraph has been added to the new version of the manuscript in order to explain the future work using these catalysts:

"In order to complete this study, deeper analysis of the activity and stability of catalysts, in isothermal reaction conditions, as well as under diesel conditions for comparative purpose, is now in process."

Specific comment:

1) Abstract line2 and keywords: Not "Gasoline Diesel injection" but "Gasoline Direct injection

2) 2. Experiment line2: Not "Ba(CH3COOH)2" but "Ba(CH3COO)2"

3) 2. Experiment line5 and 7: Not "ammonia" but "ammonia solution or aqueous ammonia"

4) 3. Results and discussion: Not "Cu/Ba+Ti+Cu and $\mathrm{OL} / \mathrm{Ba}+\mathrm{Ti}+\mathrm{Cu}$ " but " $\mathrm{Cu} / \mathrm{Ba}+\mathrm{Fe}+\mathrm{Cu}$ and $\mathrm{OL} / \mathrm{Ba}+\mathrm{Fe}+\mathrm{Cu} "$

All the specific comments indicated have been considered and modified in the revised version of the manuscript. 